\title{
A abordagem do tema "resíduos sólidos" em livros didáticos de ciências do sexto ano do ensino fundamental
}

\author{
Approach the theme "solid waste" in textbooks of sciences of the sixth year of elementary education \\ Eliane Aparecida Nunes' e Leila Cristina Aoyama Barbosa² \\ 1,2Universidade Federal de Santa Catarina: UFSC
}

\section{Resumo}

Neste artigo, analisamos dois livros didáticos de ciências do sexto ano do ensino fundamental, quanto à apresentação da abordagem do tema resíduos sólidos (lixo). Para isso, foram observados os valores, concepções, imagens e as atividades retratadas, tendo como referencial teórico a vertente crítica da Educação Ambiental. Trata-se de uma pesquisa empírica do tipo qualitativa com coleta de dados em livros didáticos. Como resultados, identificamos que os conteúdos abordados nos livros didáticos analisados precisam ser escritos e retratados de forma mais crítica, considerando que os temas, para serem significativos, precisam estar relacionados com a realidade social, política e econômica dos educandos, sendo apresentados de forma dinâmica, promovendo o diálogo e o pensar em atitudes ambientalmente saudáveis. Palavras-chave: educação ambiental, análise de livro didático, lixo.

\begin{abstract}
In this paper, we analyze two science textbooks, the sixth year of elementary school, as the presentation of the approach to the subject solid waste. For it has been observed values, conceptions, images and activities portrayed as the theoretical framework Critical Environmental Education. It is an empirical research, qualitative type, with data collection in textbooks. As a result, we found that the content covered in the textbooks examined need to be written and portrayed more critically, considering that the topics to be meaningful, must be related to the social, political and economic of the students and presented dynamically promoting dialogue and thinking about attitudes healthy environmental. Keywords: environmental education, textbook analysis, waste.
\end{abstract}




\section{INTRODUÇ̃̃O}

As questões ambientais vêm sendo discutidas amplamente em sociedade devido às grandes mudanças que percebemos no ambiente mundial, como a escassez de água, as mudanças climáticas, o aquecimento global, os diversos tipos de poluição, entre outros (DIAS, 1993). Essa discussão é trazida ao ambiente escolar por recomendação dos Parâmetros Curriculares Nacionais (PCNs) que considera o tema "meio ambiente" como transversal ao ensino (BRASIL, 1997).

A temática ambiental pode se fazer presente nas diversas disciplinas escolares. No entanto, há uma preferência em tratá-la no ensino de ciências pela relação direta de alguns dos seus conteúdos com o meio ambiente.

Ao se pensar nas possibilidades de trabalhar a temática em sala de aula, identifica-se o livro didático (LD) como um dos principais instrumentos para o planejamento de aulas pelos professores e para a aprendizagem dos alunos (LAJOLO, 1996). No Brasil, a política de utilização deste material didático se firmou com a Legislação do Livro Didático, pelo Decreto-Lei n. ${ }^{\circ} 1.006$, de 30 de dezembro de 1938 (FRANCO, 1992). O LD nessa época era uma ferramenta da educação política e ideológica. O Estado era controlador quanto ao uso desse material e sua escolha era feita pelo professor, que recebia uma lista pré-determinada contendo as opções disponíveis.

Atualmente, o professor continua participando da escolha do material a ser adotado em suas aulas. Isso é possível pelo Programa Nacional do Livro Didático (PNLD), cujo objetivo é garantir a aquisição e distribuição gratuita deste material a alunos de escolas públicas brasileiras.

Todos os títulos de LD que podem ser distribuídos às escolas são preliminarmente avaliados quanto à qualidade de conteúdo, ilustrações, tipos de exercícios propostos, entre outros critérios. Entretanto, investigações já realizadas afirmam que muitos destas obras apresentam fundamentos conceituais científicos que facilitam uma visão errônea de ciências ou apresentam fragilidades em seus conceitos. Megid Neto e Fracalanza (2003) ao analisar LD de ciências identificaram as fragilidades nos fundamentos conceituais referentes ao termo meio ambiente. Para os pesquisadores, as temáticas ambientais são apresentadas somente nas páginas iniciais dos livros, porém não se efetiva nos textos, atividades propostas ou nas orientações metodológicas fornecidas aos professores.

Neste sentido, o LD se torna objeto de investigação deste trabalho para se verificar o modo como alguns deles apresentam o tema ambiental "resíduos sólidos". A escolha da temática se fez pela controvérsia existente nele, pois muitas pessoas associam a solução do problema do lixo produzido à reciclagem, enquanto Layrargues (2002) alerta que a política dos $3 \mathrm{R}^{\prime} \mathrm{s}^{1}$ e a coleta seletiva de lixo tornaram-se instrumentos do mercantilismo para permitir o consumismo exacerbado pela sociedade. Desse modo, nosso objetivo é verificar se o tema em questão é contextualizado e problematizado no sexto ano do ensino fundamental ou se se apresenta de modo ingênuo e ainda caracterizado pelas vertentes conservacionista ou pragmática ${ }^{2}$ de educação ambiental (EA).

Este artigo é um recorte de uma monografia $^{3}$ produzida em um curso de pós-graduação lato senso em Ensino de Ciências.

\section{ASPECTOS METODOLÓGICOS}

O trabalho é uma pesquisa qualitativa de natureza empírica. A pesquisa qualitativa caracteriza-se como um avanço para as ciências humanas porque preenche os espaços que o modelo quantitativo não alcança. Para Minayo (2001), a pesquisa qualitativa trabalha com o universo de significados, motivos, crenças, valores e atitudes, o que corresponde a um espaço mais profundo das relações, dos processos e dos fenômenos que não podem ser reduzidos à operacionalização de variáveis.

Também utiliza de pesquisa bibliográfica para a elaboração de categorias para análise da temática "resíduos sólidos - lixo", em livros didáticos de ciências do sexto ano do ensino fundamental, a fim de compreender o modo como este conteúdo apresenta valores, concepções, imagens e as atividades em uma perspectiva da educação

\footnotetext{
'A Política dos 3R's é assim denominada pelo significado das três ações/cuidados que devemos ter com a produção do lixo: "Reduzir", "Reutilizar" e "Reciclar".

${ }^{2}$ A educação ambiental conservacionista tem por objetivo despertar a sensibilização ecológica dos envolvidos num lema bastante divulgado na década de 1980: "conhecer para amar, amar para preservar". Na década de 1990, surge a educação ambiental pragmática, cujo viés dava continuidade a educação ambiental conservacionista, porém com o foco em ações realizadas em um ecossistema urbano, como por exemplo, as atividades de coleta seletiva de lixo (LAYRARGUES \& LIMA, 2011)

${ }^{3} \mathrm{XXX}$. A abordagem do tema resíduos sólidos no meio ambiente nos livros didáticos de ciências do sexto ano do ensino fundamental. 2013. $49 \mathrm{f}$. Monografia - Programa de Pós-Graduação Lato Senso em Ensino de Ciências, Instituto Federal de Educação, Ciência e Tecnologia de Santa Catarina, 2013.
} 
ambiental crítica ${ }^{4}$.

Foram selecionados dois livros didáticos de ciências do sexto ano do ensino fundamental, que foram distribuídos a escolas estaduais pelo PNLD para serem analisados: 1) Ciências: o meio ambiente (BARROS, 2011); 2) Ciências naturais: aprendendo com o cotidiano (CANTO, 2009).

Os dados coletados para análise foram referentes às informações apresentadas nos capítulos dos LD referente ao tema resíduos sólidos - lixo. Para análise dos aspectos pedagógicos foram considerados a vertente da EA crítica, os PCNs e as concepções de meio ambiente conceituadas pelos autores Reigota (1998) e Abilio et al. (2004).

\section{I Categorias levantadas para análise dos resultados}

Reigota (1998) menciona a educação ambiental dentro de uma proposta pedagógica centrada na conscientização, participação efetiva do educando, mudança de comportamento e desenvolvimento da capacidade do educando de avaliar e ter atitude em relação ao meio ambiente.

Já para Abilio et al (2004), a proposta pedagógica deve propiciar uma nova percepção nas relações entre o homem e a natureza, assim como reforçar a necessidade do homem agir como cidadão na busca de soluções para problemas regionais. Os aspectos pedagógicos no LD de Ciências, em relação ao meio ambiente, devem propiciar a reflexão considerando a realidade social do aluno, promovendo a ampliação do relacionamento do sujeito com o meio social, econômico, político e cultural.

Carvalho (2008) alerta que os temas ambientais necessitam ser abordados de forma abrangente, sendo mais que o repasse de informações, mas propiciando "processos de formação do sujeito humano, instituindo novos modos de ser, de compreender, de posicionar-se ante os outros e a si mesmo, enfrentando os desafios e as crises do tempo em que vivemos" (CARVALHO, 2008, p.69).

Os PCNs ressaltam que as questões pedagógicas devem "proporcionar oportunidades para que o aluno possa utilizar o conhecimento sobre o Meio Ambiente para compreender a sua realidade e atuar sobre ela" (BRASIL, 1997, p.35). Por isso, os conteúdos a serem trabalhados precisam estar ligados à prática da reflexão, facilitando a compre-

\footnotetext{
${ }^{4}$ Segundo Loureiro (2003) a EA Crítica é aquela que articula a dimensão social com a ecológica, além de vislumbrar as dimensões política e econômica na tentativa de discutir coletivamente sobre os problemas estruturais de nossa sociedade.
}

ensão e aprendizado para os alunos. Por exemplo, os procedimentos que podem ser abordados no ambiente escolar são:

manutenção da limpeza do ambiente escolar (jogar lixo nos cestos, cuidar das plantas da escola, manter o banheiro limpo) ou formas de evitar o desperdício, até como elaborar e participar de uma campanha ou saber dispor dos serviços existentes relacionados com as questões ambientais (por exemplo, os órgãos ligados à prefeitura ou as organizações não-governamentais que desenvolvem trabalhos, exposições, oferecem serviços à população, possuem material e informações de interesse da escola e dos alunos, etc.) (BRASIL, 1997, p. 37).

O conteúdo do meio ambiente proposto aqui deverá trazer uma "visão ampla que envolva não só os elementos naturais do meio ambiente, mas também os elementos construídos e todos os aspectos sociais envolvidos na questão ambiental" (BRASIL, 1997, p.52). Desse modo, nota-se que os próprios documentos oficiais da educação defendem a vertente crítica da EA.

O conceito de meio ambiente, segundo os PCNs (BRASIL, 1997), é um processo em construção porque é amplo e envolve toda ação humana. Mas o termo "meio ambiente tem sido utilizado para indicar um "espaço" (com seus componentes bióticos e abióticos e suas interações) em que um ser vive e se desenvolve, trocando energia e interagindo com ele, sendo transformado e transformando-o" (BRASIL, 2007, p.21).

Neste sentido, na escola, os valores são refletidos na vivência dos alunos onde se permite que os mesmos se apropriem de atitudes e valores de respeito ao meio ambiente, atitudes estas que serão determinantes também em sua vida fora da escola.

Reigota (1991) aponta três concepções distintas de meio ambiente que podem ser utilizadas para analisar as atividades propostas nos livros didáticos: naturalista, antropocêntrica e globalizante.

A visão naturalista considera o meio ambiente como sinônimo de natureza intocada; evidenciam-se somente os aspectos naturais. A antropocêntrica considera a utilidade dos recursos naturais para a sobrevivência do ser humano. E a globalizante aborda as relações recíprocas entre natureza e sociedade. 
Também, Abílio et al. (2004) consideram importante para análise dos conteúdos dos livros didáticos as categorias: a) visão antropocêntrica utilitarista: considera a natureza como uma fonte de recursos, fornecedora de vida ao homem em que a natureza é vista como uma estrutura isolada do homem; b) visão biocêntrica: vê o ser humano como mais um ser vivo que está inserido no meio ambiente e esse meio não necessariamente seja útil para o homem - essa visão se diferencia da antropocêntrica porque ela não depende da utilidade que o Meio Ambiente possui ter ao ser humano; c) visão naturalista: a natureza oferece o meio ambiente onde seres vivos habitam e os fatores abióticos, ela é tudo o que não sofreu ação de transformação pelo homem, tais como as matas, bichos, os alimentos e d) a visão generalizante: muito extenso, abstrato e vago, pois equivale natureza à meio ambiente.

As concepções fornecidas por estes pesquisadores, apesar das nomenclaturas diferentes, divergem em significados e podem auxiliar educandos e educadores a terem uma consciência ambiental mais crítica enquanto outras mantêm uma perspectiva mais conservadora da EA.

\section{ANÁLISE E DISCUSSÃO DOS RESULTA- DOS}

Os livros didáticos são escolhidos pelas escolas públicas conforme o Guia de livros didáticos do Plano Nacional do Livro Didático - PNLD, do Ministério da Educação Os critérios da forma como é escolhido são definidos pela secretaria de educação municipal e estadual. Os livros analisados nesse trabalho foram:

1) BARROS, C., PAULINO, W. R. Ciências o meio ambiente. São Paulo: Ática, 2011.

2) CANTO, E. L. Ciências naturais: aprendendo com o cotidiano. São Paulo: Moderna, 2009.

O livro de Barros e Paulino (2011) está organizado por unidades e dentro delas, os capítulos. Os temas gerais mencionados são: Os seres vivos e o ambiente, a Terra dentro e por fora, a água no ambiente, o ar e o ambiente, desequilíbrios ambientais e o ambiente maior.

No capítulo de "Apresentação" do livro ao aluno, os autores escrevem que os conteúdos e atividades propostas visam à formação de uma mentalidade crítica, através da participação ativa, para que possam melhor compreender o mundo e suas transformações, agindo de forma responsável em relação ao meio ambiente.
O livro aponta como objetivo principal estimular o interesse na busca de saberes diante das oportunidades que envolvem os conhecimentos, procedimentos e atitudes, seguindo as determinações dos PCNs.

\section{Como reduzir o lixo}

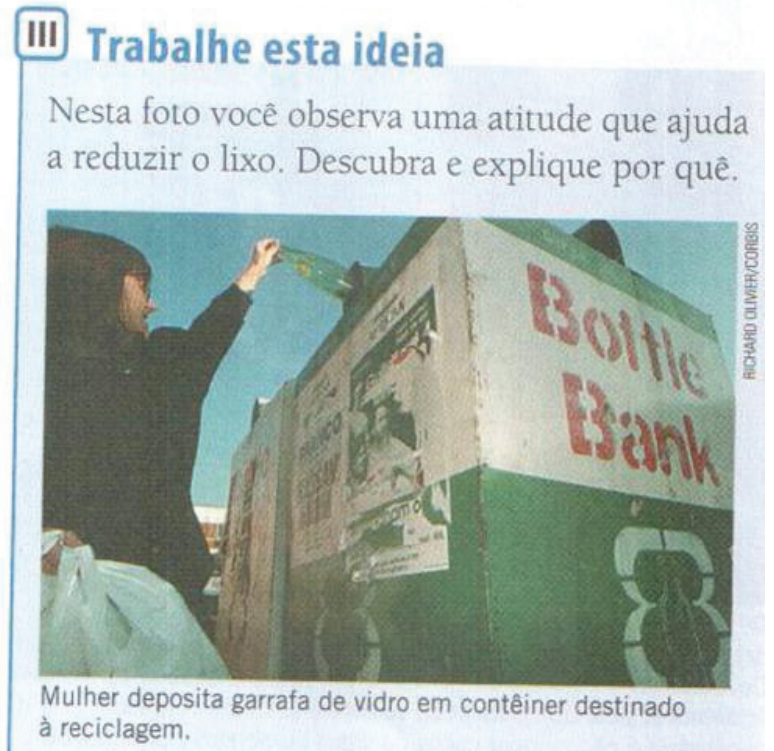

Figura 1: Seção Trabalhe esta Ideia do livro de Barros e Paulino (2011)

Fonte: Barros e Paulino, 2011, p. 228.

Neste livro há um capítulo sobre desequilíbrios ambientais, com os temas: poluição ambiental (efeito estufa, perigo no ar, as chuvas ácida, espuma na água, agrotóxicos, avanço tecnológico e os problemas) e lixo: problemas e soluções (tipos de lixo, destino do lixo e coleta do lixo). O capítulo inicia com um pequeno texto, uma imagem, seguindo-se alguns questionamentos vinculados ao tema a ser tratado. Em seguida, há o desenvolvimento do tema em um tópico intitulado "Trabalhe esta ideia" (Figura 1). Essa atividade solicita que o aluno participe e antecipe determinado conteúdo conceitual que será abordado ao longo do texto a partir de observações do cotidiano.

Em seguida há apresentação de um "Mapa de Conceitos" (Figura 2) que cumpre seu papel de trazer informações sobre os resíduos sólidos. Nota-se a divulgação da política dos 3 R's e de destinos do lixo, porém sentimos falta de um olhar mais crítico que contextualiza a realidade e associa os problemas ambientais com questões sociais. 


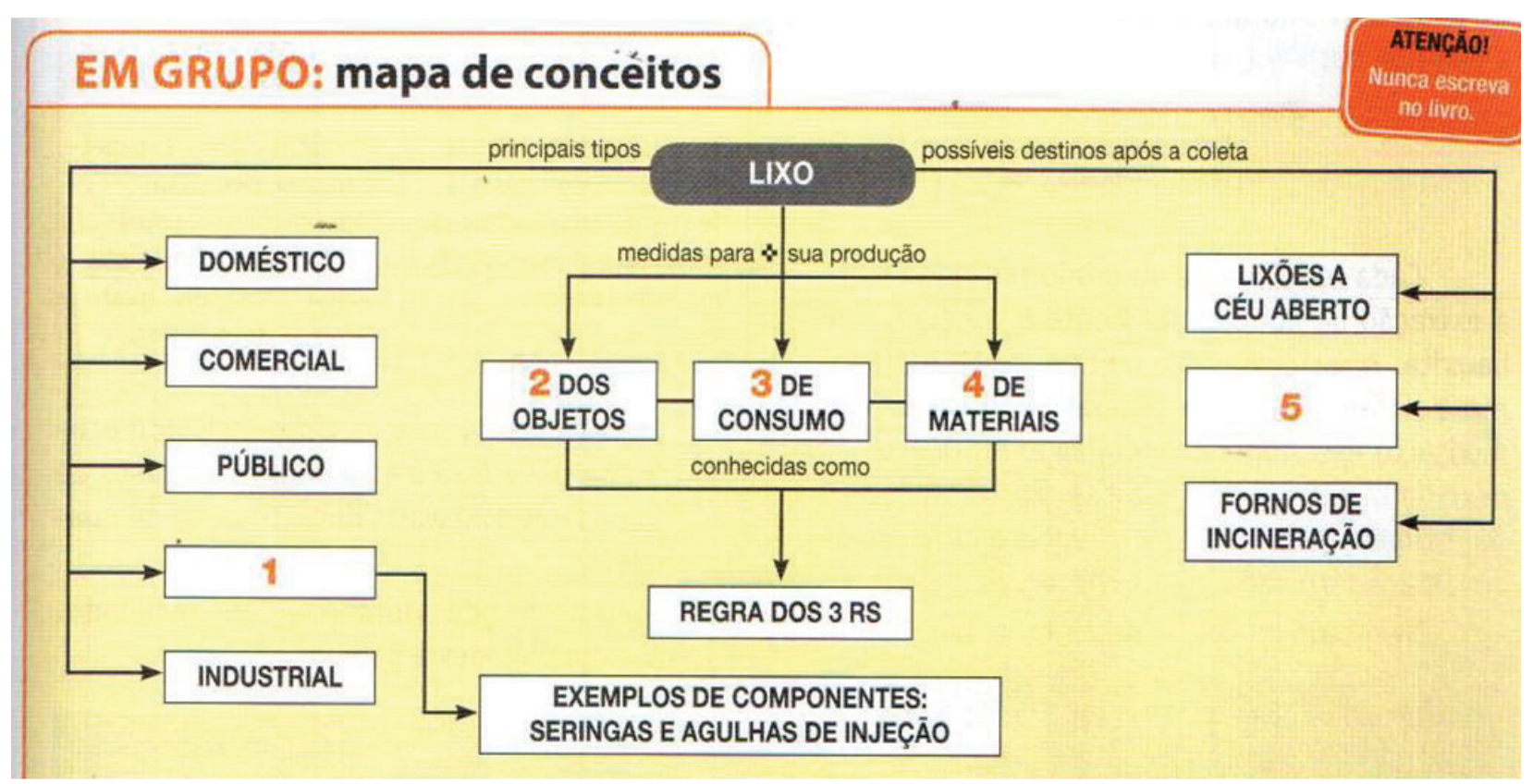

Figura 2: Mapa Conceitual sobre o conteúdo resíduos sólidos do livro didático de Barros e Paulino (2011).

Fonte: Barros e Paulino, 2011, p. 229.

Em outro tópico, "Para ir mais longe" (Figura 3), o livro busca um aprofundamento dos assuntos trabalhados no capítulo, mas não aponta questionamentos no sentido de despertar a reflexão sobre os assuntos estudados, desta forma cabe ao professor dentro de seus critérios e concepções fazer conduzir o trabalho de forma reflexiva e crítica.
A seção "Desafios do Presente" (Figura 4), encontrada nesse capítulo, apresenta um texto que, de acordo com a proposta do autor, deveria provocar o aluno a interagir com o conhecimento buscando alternativas para o problema abordado. Mas não se encontram questionamentos ou direcionamentos para esse propósito de reflexão e busca de soluções. Isto sinaliza que caso o professor não tenha uma formação crítica apropriada, o estudo

\section{PARA IR MAIS LONGE}

\section{Tempo de decomposição}

0 tempo de decomposição de um material na natureza depende de vários fatores ambientais, como umidade e calor. Materiais orgânicos, como restos de frutas e panos, são naturalmente decompostos por bactérias e fungos. Já materiais inorgânicos, como vidro e latas de aço, não são decompostos por seres vivos - eles se degradam lentamente pela ação de certos agentes químicos.

$\mathrm{Na}$ tabela ao lado, verifique o tempo aproximado de decomposição de alguns materiais submetidos a condições ambientais semelhantes às existentes, por exemplo, no aterro sanitário Bandeirantes, em São Paulo.

\begin{tabular}{|l|l|}
\hline \multicolumn{1}{|c|}{ Material } & \multicolumn{1}{c|}{ Tempo de decomposição } \\
\hline papel & 3 meses \\
\hline palito de fósforo & 6 meses \\
\hline pano & 6 meses a 1 ano \\
\hline restos de frutas & 6 meses a 1 ano \\
\hline filtro de cigarro & 1 a 2 anos \\
\hline chiclete & 5 anos \\
\hline lata de aço & 10 anos \\
\hline garrafa de plástico & 100 anos, no mínimo \\
\hline fralda descartável & 600 anos \\
\hline garrafa de vidro & 1000 anos, no mínimo \\
\hline
\end{tabular}

Figura 3: Seção Para ir mais Longe do livro didático de Barros e Paulino (2011).

Fonte: Barros e Paulino, 2011, p. 229. 


\section{Desafios do presente}

\section{A reciclagem no Brasil}

Novos números sobre reciclagem no Brasil mostram que o país reaproveita apenas cerca de $10 \%$ de tudo o que joga na lata de lixo - cinco vezes menos do que nos países desenvolvidos.

Apesar disso, o Brasil é o campeão mundial no reaproveitamento de latas de alumínio e de garrafas PET. Mas os plásticos em geral e latas de aço têm como destino preferencial os lixões a céu aberto.

Wenserg, M. Comece a reciclar. Veja, n. 35 5 de setembro de 2007, p. 118-120. (Texto adaptado para fins didáticos.)

Cada tonelada de alumínio reciclado evita extração de aproximadamente 5 toneladas de bauxita. A reciclagem de metais, como 0 alumínio e o ferro, além de poupar os minérios dos quais são extraídos, economiza energia elétrica destinada à produção desses metais, reduz a quantidade de lixo e preserva o ambiente da devastação causada pela extração de minérios. Verifique os dados desta tabela:

\begin{tabular}{|l|l|}
\hline $\begin{array}{c}\text { Objetos feitos de metais } \\
\text { recicláveis }\end{array}$ & $\begin{array}{c}\text { Objetos feitos de metais } \\
\text { năo recicláveis }\end{array}$ \\
\hline $\begin{array}{l}\text { Latas de aço, latas de alu- } \\
\text { mínio, tampas de metal. }\end{array}$ & $\begin{array}{l}\text { Clipes, grampos, esponjas } \\
\text { de aço, canos. }\end{array}$ \\
\hline
\end{tabular}

Cada tonelada de papel reciclado pode poupar de 15 a 20 árvores. Portanto, a reciclagem de papel contribui para evitar o desmatamento. Além disso, economiza uma quantidade de energia suficiente para abastecer uma casa média por cerca de seis meses.

Mas nem todo tipo de papel pode ser reciclado. Veja na tabela abaixo alguns exemplos:

\begin{tabular}{|c|c|}
\hline Papéis recicláveis & Papéis não recicláveis \\
\hline $\begin{array}{l}\text { Jornais, revistas, folhas } \\
\text { de caderno, formulários } \\
\text { de computador, caixas em } \\
\text { geral, envelopes, carta- } \\
\text { zes, papel de fax. }\end{array}$ & $\begin{array}{l}\text { Etiquetas adesivas, papel- } \\
\text {-carbono, fita crepe, } \\
\text { papel higiênico, papel } \\
\text { metalizado, papel plasti- } \\
\text { ficado, papel sujo, guar- } \\
\text { danapos, fotografias. }\end{array}$ \\
\hline
\end{tabular}

Uma única garrafa de vidro reciclado economiza energia elétrica equivalente ao gasto de uma lâmpada de 100 watts durante cerca de quatro horas.

Mas nem todo vidro pode ser reciclado. Veja os exemplos desta tabela:

\begin{tabular}{|l|l|}
\hline \multicolumn{1}{|c|}{ Vidros recicláveis } & Vidros não reciclâveis \\
\hline $\begin{array}{l}\text { Garrafas, copos e frascos } \\
\text { de vidro comum. }\end{array}$ & $\begin{array}{l}\text { Espelhos, tristais, lâmpa- } \\
\text { das, tubos de televisão. }\end{array}$ \\
\hline
\end{tabular}

Figura 4: Seção Desafios do Presente do livro didático de Barros e Paulino (2011).

Fonte: Barros e Paulino,2011, p. 230.

sobre os resíduos sólidos ficará somente restrito aos conteúdos fornecidos pelo livro sem alguma problematização com a realidade dos alunos.

Há também uma seção - "Integrando o Conhecimento" (Figura 5), que são questões para que o aluno trabalhe os conceitos estudados no capítulo que devem ser respondidas utilizando os conhecimentos adquiridos no estudo do capítulo. Aqui a atividade exige uma cobrança de conteúdo conceitual, com maior ou menor necessidade de reflexão e relação com o cotidiano e o conteúdo.

A seção "Em grupo: Ligados no Ambiente" (Figura 6) propõe estimular o aluno a trabalhar em grupo buscando novas informações, desenvolvendo a análise diante de imagens e frases. Essa atividade é importante no sexto ano para desenvolver a análise em grupo, provocar o aluno a pensar na relação de lazer, produção e consumo. Nota-se que a questão procura trabalhar sobre questões ecológicas, no entanto, foge da temática dos resíduos

\section{IN TE GRANDO O CONHECIMENTO}

1. Organismos mortos ou restos e resíduos de seres vivos eliminados no ambiente (folhas, frutos, pele, fezes) são naturalmente decompostos por microrganismos. O lixo orgânico pode ser separado e usado nas usinas de compostagem, onde é parcialmente decomposto pela ação de microrganismos. Obtém-se assim o composto, um material rico em nutrientes diversos. No Brasil, existem várias usinas de compostagem, capazes de produzir até mais de 400 toneladas de composto por dia. a) Qual o uso que as pessoas podem dar ao composto obtido nas usinas de compostagem?

b) Por que se diz que a compostagem ocorre normalmente na natureza? Quais são os organismos responsáveis por esse processo?

2. Grande parte dos alimentos produzidos na agricultura se perde e vai para o lixo. Identifique dois procedimentos humanos associados a esse desperdício.

Figura 5: Seção Integrando o Conhecimento do livro didático de Barros e Paulino (2011).

Fonte: Barros e Paulino, 2011, p. 230. 
sólidos ou de relações diretas com ela. Poderia ter sido desenvolvida uma questão sobre a relação da produção de lixo e o consumismo das pessoas. lixo que ele produz.

A obra recomenda reduzir o lixo dando um destino certo a ele, sugerindo ao final do capítulo

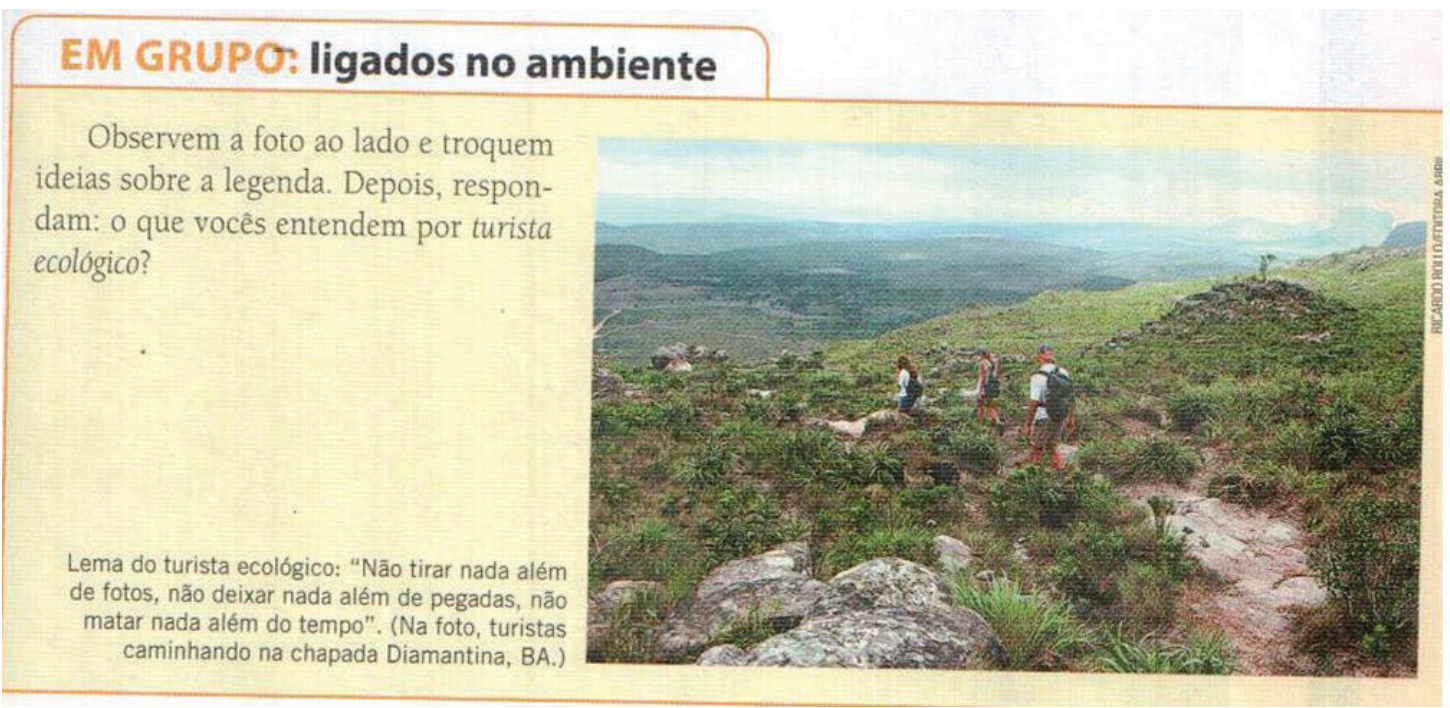

Figura 6: Seção Em grupo- Ligados no Ambiente do livro didático de Barros e Paulino (2011).

Fonte: Barros e Paulino, 2011, p. 231.

No final do capítulo, há sugestões de leitura relacionada ao tema. Essa seção é denominada "Você vai Gostar de Ler" (Figura 7). Importante destacar que os autores ressaltam que o conhecimento não se esgota em si mesmo e apresentam outras fontes para o aluno aprofundar o conteúdo. que seja discutido em grupo as medidas que podem ser utilizadas para minimizar o problema. Na obra, a visão antropocêntrica se destaca na concepção do meio ambiente mencionada: "A ecologia é uma ciência que contribui para uma relação mais harmoniosa e produtiva dos seres humanos com

\section{Você vai gostar de ler}

\section{unidade V}

- Caça ao tesouro - Uma viagem ecológica. Liliana lacocca e Michelle lacocca, Ática,

- Chuva ácida. M. Bright, Melhoramentos. Coleção SOS Planeta Terra.

- Efeito estufa. M. Bright, Melhoramentos. Coleção SOS Planeta Terra.

- Lixo e reciclagem. Barbara James, Scipione. Coleção Preserve o Mundo.

- Lixo - de onde vem? Para onde vai? Francisco Luiz Rodrigues e Vilma Maria Cavinatto, Moderna.

- Natureza e agroquímicos. Samuel Murgel Branco, Moderna.

- O luxo do lixo. Mariane Lachmann, Gryphus.

- O menino que quase morreu afogado no lixo. Ruth Rocha, FTD.

- O saci e a reciclagem do lixo. Samuel Murgel Branco, Moderna.

- Poluição do tráfego. M. Bright, Melhoramentos. Coleção SOS Planeta Terra.

Figura 7: Seção Você vai Gostar de Ler do livro didático de Barros e Paulino (2011).

Fonte: Barros e Paulino, 2011, p. 231.

Pode-se verificar, diante da análise, a presença da visão antropocêntrica e utilitarista de meio ambiente (ABÍLIO et al., 2004), em que se buscam formas de sensibilizar o aluno para a dimensão ambiental propondo refletir sobre sua produção diária de lixo e suas atitudes diante do a natureza" (BARROS, PAULINO, 2011, p.13).

Neste sentido, torna-se um desafio propor uma EA crítica diante das concepções de meio ambiente presentes na obra, na qual leva o aluno a alienação e reforça a relação de antropocentrismo, porque a reflexão está focada na ação exploratória 


\begin{tabular}{|c|c|}
\hline $\begin{array}{l}\text { Sacola plástica usada } \\
\text { gera problema ambier }\end{array}$ & $\begin{array}{l}\text { comércio } \\
\text { no Estado }\end{array}$ \\
\hline $\begin{array}{l}\text { “Hoje [8 dez. 2007], a Secretaria Estadual do } \\
\text { Meio Ambiente (SMA) promove na capital e no } \\
\text { interior do Estado [São Paulo] mutirão de cons- } \\
\text { cientização sobre o problema causado pelo uso } \\
\text { de sacolas plásticas. Esta opção de embalagem } \\
\text { é comum no comércio e supermercados, porém } \\
\text { aumenta o volume do lixo coletado nas cidades } \\
\text { e diminui a vida útil dos aterros sanitários. } \\
\text { A SMA estima em } 66 \text { milhões o número de } \\
\text { sacolas usadas a cada ano no Estado. Traz como } \\
\text { resultado a necessidade permanente de os } 645 \\
\text { municípios paulistas ampliarem os aterros e } \\
\text { deixarem de investir em educação e saúde. Das } \\
12 \text { mil toneladas de lixo geradas diariamente na } \\
\text { capital, mil são de plásticos. }\end{array}$ & 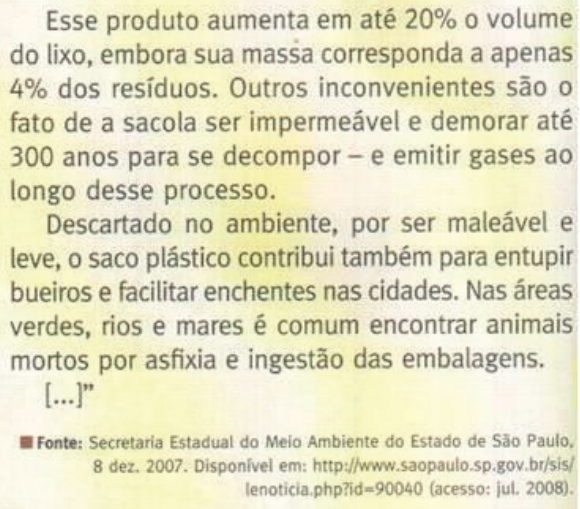 \\
\hline
\end{tabular}

Figura 8: Seção Motivação do livro didático de Canto (2009)

Fonte: Canto, 2009, p. 146.

e não de construção. Esse tipo de concepção está ligada à EA conservadora que utiliza a sensibilização, por exemplo, ensina a realizar a separação dos tipos de lixo, na chamada coleta seletiva de lixo, mas não reflete a complexidade e a origem dos problemas socioambientais.

É importante que o LD contextualize e exemplifique as ações com o cotidiano do aluno. Exemplo desta ausência são as imagens da questão do lixo nessa obra. Há uma figura de uma pessoa depositando o lixo em um contêiner abordado na seção "Trabalhe essa ideia: (Figura 01), sendo aquele recipiente fora do contexto do aluno. Percebe-se a falta de imagens de crianças plantando árvores, reciclando o lixo doméstico, lixo escolar, depositando no recipiente certo, imagens mais próximas da realidade que provoca uma ação.

A realidade dos catadores de lixo está presente no livro didático? Uma realidade presente no dia a dia do aluno, na própria escola visto que há alunos que são filhos de catadores e a coleta do lixo é uma alternativa de sobrevivência encontrada por várias pessoas. A visão ambiental crítica trata isso de forma politizada, problematizadora, questionadora, integrada aos interesses das populações e das classes sociais mais afetadas pelos problemas socioambientais.

O segundo livro analisado de CANTO (2009), está organizado em capítulos com quatro eixos temáticos: Vida e Ambiente; Ser Humano e Saúde; Terra e Universo; Tecnologia e Sociedade. Por estes eixos temáticos, são abordados vários estudos que favorecem a aprendizagem signifi- cativa dos conteúdos. Essa organização propõe a interdisciplinaridade, mas não de modo explícito. $\mathrm{O}$ autor faz uma carta aos pais e alunos apresentando sua proposta de incentivo a utilizar o livro para a construção do conhecimento.

Os conteúdos são abordados a partir da problematização, direcionados para a integração dos diversos contextos que permeiam os conceitos científicos escolares. Os conteúdos tem uma proximidade ao aluno, a realidade em que ele vive e o entendimento da sociedade em que está inserido

A seção "Motivação" (Figura 8) vem acompanhada de uma imagem com um breve comentário com a intenção de despertar a curiosidade do aluno. Em destaque nesta seção é um texto retirado de um site da Secretaria Estadual do Meio Ambiente do Estado de SP, apresentando a realidade da sacola plástica.

"Desenvolvimento do Tema" (Figura 9) é outra seção que aborda o lixo de maneira contextualizada ao cotidiano dos alunos. $\mathrm{O}$ trabalho em equipe provoca a discussão e análise da realidade de cada aluno diante do que é produzido em sua casa e coletivamente. Estes dados são sistematizados em forma de tabela. Saindo da reflexão do cotidiano do aluno, apresenta texto de uma grande cidade, alternativas como compostagem, reciclagem e um texto sobre o desenvolvimento sustentável. As atividades propostas conduzem a reflexão e a transformação diante da realidade. A visão não fica somente na realidade apresentada; há uma visão de mundo diante do que está sendo estudado. 


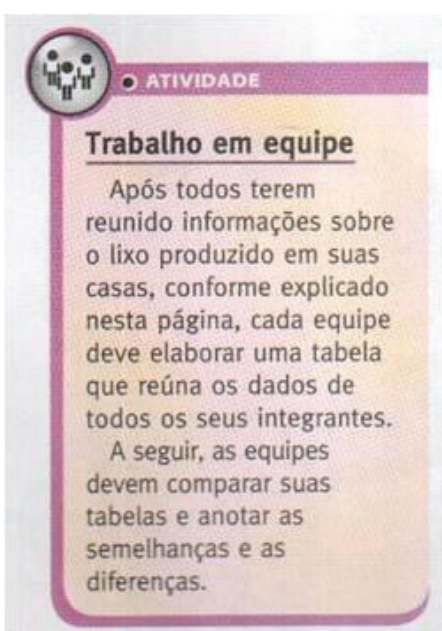

DESENVOLVIMENTO DO TEMA

\section{O nosso lixo de cada dia}

A grande quantidade de lixo produzido em uma cidade traz problemas. Há a necessidade de espaço para construir aterros sanitários. A coleta do lixo e a manutenção do aterro custam dinheiro. Mau cheiro e propagação de doenças também são problemas principalmente quando não há aterros sanitários ou quando eles são operados de modo incorreto ou não são bem construídos.

Haverá um meio de reaproveitar o lixo? Se houver, isso significa que é possível diminuir os problemas causados por ele. A resposta a essa pergunta é o assunto deste capítulo.

Para entender as ideias que serão mostradas, é útil que você anote em uma folha de papel tudo o que é colocado no lixo por você e pelos outros moradores da sua casa, durante um dia. Por exemplo:

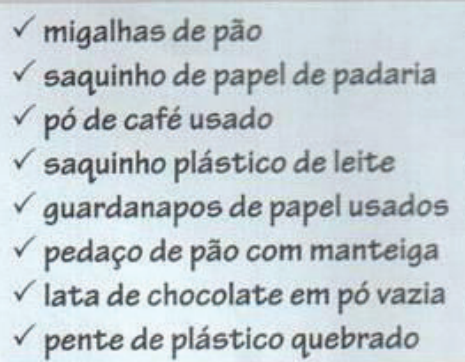

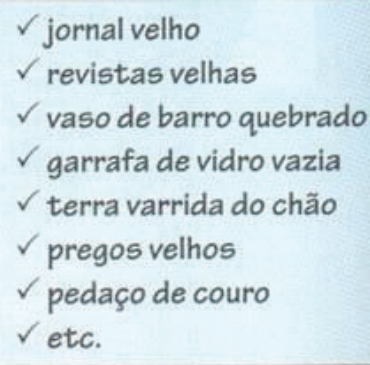

Figura 9: Seção Desenvolvimento do Tema do livro didático de Canto (2009).

Fonte: Canto, 2009, p. 146.

A seção "Organização de Ideias" (Figura 10) traz um mapa conceitual elaborado de acordo com que foi estudado na seção de motivação. Repara-se que, assim como no outro LD analisado, o mapa conceitual se prende a conteúdos enquanto poderia ter também uma dimensão social.

As últimas seções são: "Use o que Aprendeu" e "Explore Diferentes Linguagens" (Figura
11). Nessas seções tem vários exercícios que contempla os conceitos estudados e sua aplicabilidade com problemas práticos. O que observa que há incentivo nas atividades envolvendo outras disciplinas podendo realizar um trabalho coletivo com outros professores. Motiva uma ação conjunto entre os professores.

\section{ORGANIZAÇĀO DE IDEIAS: MAPA CONCEITUAL.}

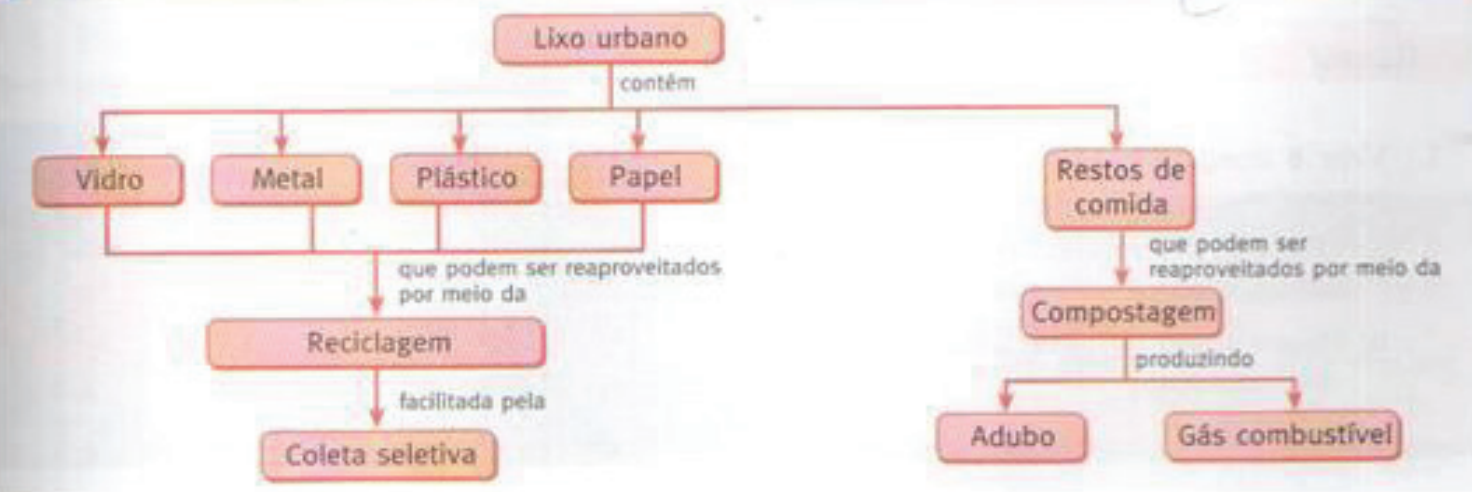

Figura 10: Seção Organização de Ideias: Mapa Conceitual, do livro didático de Canto (2009).

Fonte: Canto, 2009, p. 155. 

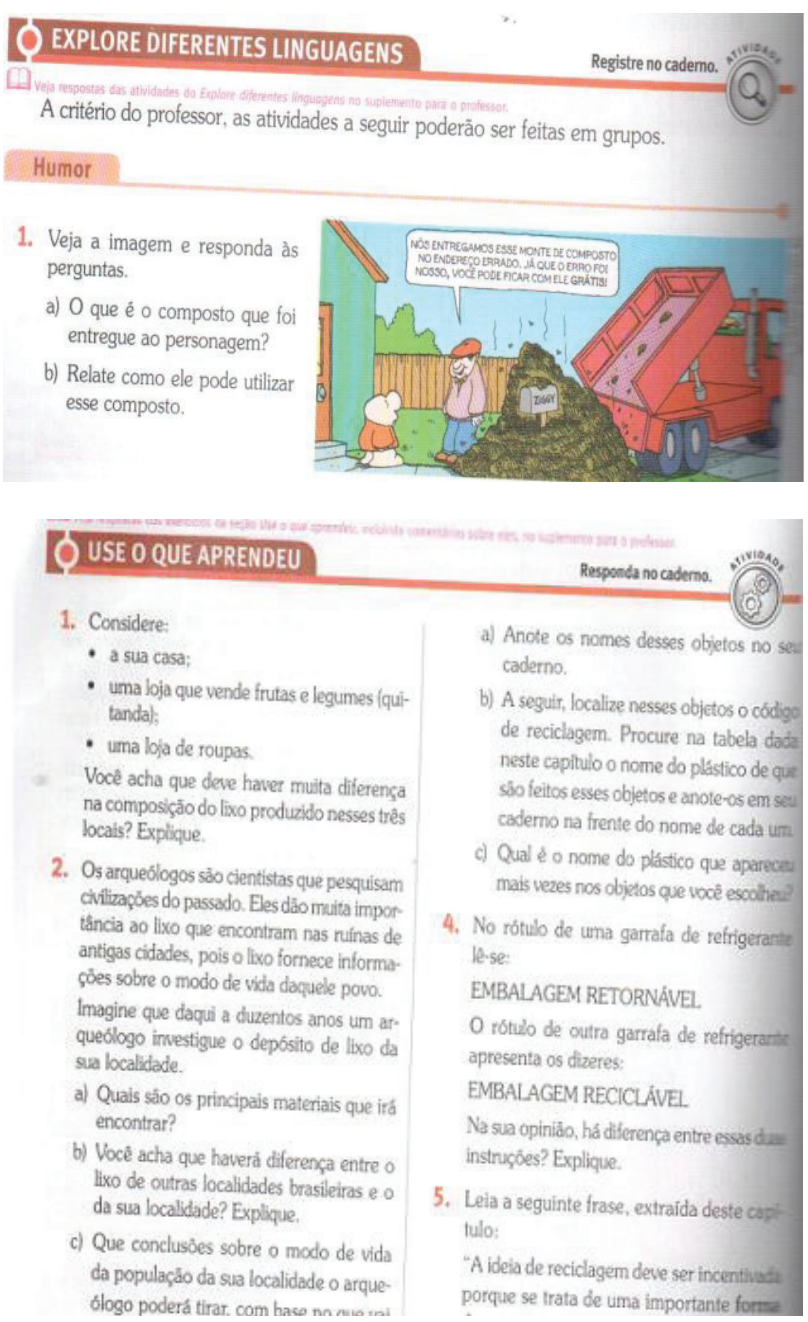

Figura 11: Seções Use que Aprendeu e Explore Diferentes Linguagens do livro de Canto (2009)

Fonte: Canto, 2009, p. 156.

Os conteúdos trabalhados sobre o lixo no LD de Canto (2009) dá maior ênfase ao reaproveitamento de materiais através de situações-problemas como mostra figura 11, na atividade "Explore Diferentes Linguagens". A discussão de situações-problemas motiva os alunos a uma reflexão sobre as atitudes que realizam no dia a dia que causam degradação ambiental e desperdício, as implicações ambientais decorrentes dessas ações e quais medidas poderiam ser tomadas para evitar esses tipos de problemas.

Para Guimarães (2004, p.101) "não basta mais apenas sabermos o que é certo ou errado em relação ao meio ambiente, é necessário uma mudança de atitude nossa com nós mesmos, em uma nova visão de mundo; nossa com os outros e o meio ambiente que nos envolve".

Neste sentido, a visão globalizante de meio ambiente, descrita por Reigota (1991) está muito presente no livro didático de Canto, (2009), por- que busca mostrar as relações recíprocas entre natureza e sociedade. Também tem a presença da visão antropocêntrica e utilitarista (ABÍLIO et al., 2004), expressa nas atividades de sensibilização do aluno em relação a produção do lixo e sua atitudes, ressaltando o consumismo que gera mais lixo. Mas diferente de Barros e Paulino (2011), a obra de Canto (2009) apresenta uma visão mais globalizada porque o conteúdo se aproxima da realidade do aluno. As imagens e textos motivam a perceber a realidade que se vive e construir atitudes de cunho social voltada a formação de um aluno ecológico, com capacidade de análise e participação.

Nenhuma das duas obras aborda a questão da produção do lixo no meio rural, onde não passa a coleta. Eis a questão: onde jogar o lixo se o caminhão não passa recolhendo? Para onde encaminho o esgoto da casa, se não há saneamento no bairro? Como construir casa longe dos córregos e barrancos escorregadios, se não tem outro lugar para morar? Que novos hábitos podem ser desenvolvidos?

O lixo nesse sentido entra como uma metáfora para esconder o problema social que a população vive. E esta realidade não está presente nos LD.

Portanto, os PCNs e a EA crítica propõem a articulação da questão ambiental - neste estudo, o lixo com outras dimensões (social, econômica e política), tendo o ser humano como parte integrante do meio em que vive e não apenas como ser, objeto externo e destruidor deste meio. É fundamental oportunizar ações que visem a qualidade de vida do e no meio em que se vive.

\section{CONCLUSÃO}

A partir dos resultados obtidos, pôde-se concluir que, dos dois LD de ciências analisados, a forma como apresentam o conteúdo meio ambiente, por meio da temática "resíduos sólidos-lixo" para o sexto ano do ensino fundamental, expressam a falta de conteúdos que podem subsidiar a educação para a cidadania em relação à temática analisada.

Um dos livros didáticos oferece maior abertura nesse sentido de formação de valores e atitudes junto ao aluno quanto a sua percepção, identificação, e construção de atitudes com relação à questão do lixo de seu cotidiano, porque há mais problematização do assunto que conduz à visão globalizante de meio ambiente em que a responsabilidade é de cunho social, político e econômico. $\mathrm{O}$ aluno que faz parte desse contexto precisa se sentir integrante, crítico e criativo diante 
das situações inseridas no seu meio e no mundo como um todo.

A problemática do lixo é realidade e não se pode admitir que no meio educacional seja limitada às informações sobre meio ambiente, repousadas sob o ecologismo legendado pela fauna, flora e biodiversidade, desmatamento e lixo. È muito mais abrangente e precisa estar embasado em valores, a estrutura social e política, as possibilidades de trabalho com conteúdos atitudinais, com uma educação para a cidadania e com participação social.

Diante dos estudos realizados pelos diferentes pesquisadores mencionados nesta investigação, a participação efetiva na questão do meio ambiente, sendo aqui a temática lixo é, antes de tudo, estar consciente que faz parte do meio em que vive para construir, através do conhecimento, atitudes de intervenção da realidade. As vertentes da educação ambiental são subsídios que estão presentes nos LD e que cabe ao professor identificá-las e fazer a opção mais adequada na escolha e uso do livro.

Neste sentido, o que se pode notar é que os LD não trazem uma abordagem totalmente crítica das questões ambientais, cabendo ao professor dar este rumo. Para dar esse rumo à abordagem crítica, há necessidade de formação inicial e continuada de professores para essa temática.

\section{REFERÊNCIAS}

ABÍLIO, F. J. P. et al. Meio Ambiente e educação ambiental: uma análise crítica dos livros didáticos de ciências do ensino fundamental. In: SIMPÓSIO INTERNACIONAL PROCESSO CIVILIZADOR, HISTÓRIA E EDUCAÇÃO, 8., 2004, João Pessoa. Anais... João Pessoa, 2004.

BRASIL. Parâmetros curriculares nacionais: meio ambiente, saúde .Brasília: Secretaria de Educação Fundamental, 1997.

BARROS, C.; PAULINO, W. R. Ciências o meio ambiente. São Paulo: Ática, 2011.

CARVALHO, I. C. M. Educação ambiental: a formação do sujeito ecológico. 4. ed. São Paulo: Cortez, 2008.

CANTO, E. L. Ciências naturais: aprendendo com o cotidiano. São Paulo: Moderna, 2009.

DIAS, G. F. Educação ambiental: princípios e práticas. São Paulo: Gaia, 1993.
FRANCO, M. L. P. B. O livro didático e o Estado. ANDE, ano I, n 5, 1992.

GUIMARÃES, M. A Formação de Educadores Ambientais. Campinas: Papirus, 2004.

LAJOLO, M. Livro didático: um (quase) manual do usuário. Em aberto, Brasília, ano 16, n. 69, p.03-09, jan.-mar. 1996.

LAYARGUES, P. P. O cinismo da reciclagem: o significado ideológico da reciclagem da lata de alumínio e suas implicações para a educação ambiental. LOUREIRO, F.; LAYARGUES, P. P.; CASTRO, R. (orgs.) Educação ambiental: repensando o espaço da cidadania. São Paulo: Cortez, p. 149-220, 2002.

.; LIMA, G. F. C. Mapeando as macro-tendências político-pedagógicas da educação ambiental contemporânea no Brasil. In: ENCONTRO PESQUISA EM EDUCAÇÃO AMBIENTAL, 6., 2011, Ribeirão Preto. Anais... Ribeirão Preto: USP, 2011. 1 CD-ROM.

LOUREIRO, C. F. B. Premissas teóricas para uma educação ambiental transformadora. Ambiente e educação, Rio Grande, n. 08, p. 37-54, 2003.

MEGID NETO, J.; FRACALANZA, H. O livro didático de ciências: problemas e soluções. Ciência e Educação, Bauru, v. 9, n. 2, p. 147-157, 2003

MINAYO, M. C. S. (Org.). Pesquisa social: teoria, método e criatividade. 21. ed. Petrópolis: Vozes, 2002.

REIGOTA, M. Desafios à educação ambiental escolar. In: JACOBI, P. et al. (orgs.). Educação, meio ambiente e cidadania: reflexões e experiências. São Paulo: SMA, 1998.

O que é educação ambiental. Brasiliense, São

Paulo, Brasil.1991. 